\title{
Zer egin paziente baten behar klinikoak asetzeko sendagaiak osasun- sistema publikoko farmazia-prestazioaren barruan ez badaude?
}

\section{What can we do when the pharmaceutical-provision of the public health system doesn't include the medications for our patient clinical needs?}

Josune Garcia de Andoin Barandiaran ${ }^{1}$, Maitane Umerez Igartua ${ }^{2}$, Miren Ercilla Liceaga ${ }^{1}$, June Landa Alberdi ${ }^{1}$, Larraitz Leunda Eizmendi ${ }^{1}$, Mikel Urretavizcaya Anton ${ }^{3}$, Aitziber Lizardi Mutuberria ${ }^{3}$

\author{
${ }^{1}$ Donostia Unibertsitate Ospitaleko Farmazia Zerbitzua \\ ${ }^{2}$ Mendaro Ospitaleko Farmazia Zerbitzua \\ ${ }^{3}$ Onkologikoa Fundazioko Farmazia Zerbitzua \\ josune.garciadeandoin@osakidetza.eus
}

\section{Laburpena}

Pazientearen behar kliniko konkretu baten aurrean osasun-sistema publikoko farmazia-prestazioaren barruan ez dagoen sendagairen baten beharra egon daiteke. Behar hori betetzeko hainbat aukera daude: fitxa teknikoz kanpoko erabilera (FTKE), atzerriko sendagai gisa eskuratzea, ikerketan aztergai dauden sendagaien erabilera errukiorraedo saiakuntza kliniko batean parte hartzea. Kasu horietan, eskaera berezi bat luzatu behar zaio Sendagai eta Osasun Produktuen Espainiar Agentziari (SOPEA) edo/eta ospitaleko agintariei. Aurkeztu beharreko txostenetan garbi azalduko da sendagaiaren behar ezinbestekoa eta gaixoaren baimen informatua lortzea ere derrigorrezkoa da.

\section{Gako-hitzak: fitxa teknikoz kanpoko erabilera, atzerriko sendagaia, sendagaien erabilera errukiorra}

\begin{abstract}
There may be situations where the clinical needs of a patient can not be covered with a drug included in the pharmaceutical-provision of the public health system. There are different options for obtaining it: off-label use, acquisition of a foreign medicine, compassionate use of research drug or participation in a clinical trial. In these cases, a special request must be made to the Spanish Agency for Medicines and Health Products and/or to the hospital authorities. The reports to be submitted will clearly state the essential need for the drug and it is also mandatory to obtain informed consent from the patient.
\end{abstract}

Keywords: off-label use, foreign medicine, compassionate use drug

\section{Sarrera}

Batzuetan osasun-sistema publikoko farmazia-prestazioaren barruan dauden sendagaiak ez dira nahiko behar kliniko konkretu baten aurrean eta beste aukera bat bilatu beharko da.

Pazienteen behar kliniko horiek asetzeko hainbat aukera daude:

1. Sendagaien erabilera onartutako baldintzetatik kanpo: sendagaia onartuta eta merkaturatuta dago, baina pazienteak behar duen indikazioa ez dago baimenduta edo/eta fitxa teknikoak ez du erabilera hori jasotzen. Egoera honi maiz fitxa teknikoz kanpoko erabilera (FTKE) deitzen zaio eta aurrerantzean terminologia hori erabiliko dugu.

2. Baimendu gabeko sendagaien eskuratzea Espainian: estatuan eskuragarri egon ez arren, pazientearen premiari erantzuteko sendagaia baimenduta dagoen lurralde batetik ekar daiteke atzerriko sendagai gisa. 
Josune Garcia de Andoin Barandiaran, Maitane Umerez Igartua, Miren Ercilla Liceaga, June Landa Alberdi, Larraitz Leunda Eizmendi, Mikel Urretavizcaya Anton, Aitziber Lizardi Mutuberria

3. Ikerketan dauden sendagaien erabilera errukiorra: saiakuntza klinikoko fasean dagoen edota merkaturatzeko baimen-eskaera egina duen sendagaia eskuragarri egon daiteke saiakuntzan sartuta ez dagoen gaixo batentzat oso egoera berezi batean.

4. Gaixoak saiakuntza kliniko batean parte hartzea: sendagaia eskuragarri dago saiakuntza kliniko baten barruan, pazienteak behar duen indikazioa ikerketa- fasean aurkitzen baita.

Espainiar estatuan lehen hiru kasuak egoera berezietan dauden sendagaien eskuratze-prozeduren barruan sartzen dira eta ekainaren 19ko 1015/2009 Errege Dekretuak arautzen ditu (1). Saiakuntza klinikoak, ordea, abenduaren 4ko 1090/2015 Errege Dekretuaren arabera arautzen dira (2).

Ondoren egoera bakoitzean sakonduko dugu.

\section{Sendagaien erabilera onartutako baldintzetatik kanpo: fitxa teknikoz kanpoko erabilera (FTKE)}

Gaixoak duen egoera klinikoari aurre egiteko baimendutako aukera hobeagorik ez badago, baimena eskatu beharra dago sendagai hori fitxa teknikoan onartu gabeko indikazioan erabili ahal izateko. Aukera hau betiere salbuespenezkoa izango da baimendutako alternatibarik ez dagoen kasuetara mugatuz.

Egoera honetako adibide asko izaten dira ospitaleetan. Gaixo askok sendagaia "Sendagai eta Osasun Produktuen Espainiar Agentziak" (SOPEA) bere fitxa teknikoan baimendutako indikazioetatik kanpo erabiltzeko beharra dute. Nahiz eta indikazio konkretu baten efektibitateari buruz bibliografia asko egon,sendagaia merkaturatzen duen laborategiak ez du beste indikazio horren baimena eskatzeko beharra ikusten. Indikazioa baimendu ahal izateko, saiakuntza kliniko konkretu bat abian jarri beharko luke eta horrek eragiten duen kostu handiari aurre egiteak ez dio konpentsatzen. Adibidez, mikofenolato eta takrolimus immunoezabatzaileek ez dute indikaziorik transplante hematopoietikoa hartzen duten gaixoetan; bai, ordea, organo solidoen transplanteetan. Hala ere, botika horiek transplante hematopoietikoa egiten zaien gaixo gehienetan erabiltzen dira. Transplante solido bat egin zaien gaixoek sendagai hori farmazia komunitarioan jaso dezakete inongo arazorik gabe, indikazio hori finantzatuta baitago. Transplante hematopoietikoa egin zaien gaixoek, aldiz, FTKEtik kanpo dagoelako, ospitaleko farmazietan jaso behar dute sendagai hau, bertako arduradunak tratamendua baimendu eta gero.

Bi egoerarenaurrean aurkitu gaitezke:

- Batzuetan, FTKEa gaixo konkretu batentzat bakarrik tramitatu beharra dago. Haren egoera klinikoari aurre egiteko medikuak ez du baimendutako aukerarik, baina ebidentzia zientifikoari helduta, sendagai konkretu baten erabilera eskatzen du. Kasu horietan, ospitaleko arduradunen esku dago tratamendu hori baimentzea. Horretarako, ospitaleetan diziplina anitzeko komisioak egon daitezke. Adibidez, Donostia Unibertsitate Ospitalean "Egoera Berezietarako Sendagaien" batzorde bat dago, zeinean farmazialari batzuek eta arlo ezberdinetako medikuek parte hartzen duten. Batzorde horrek FTKE eskaera guztiak ebaluatzen ditu eta tratamendu berezi hauek baimentzeko edo atzera botatzeko erabakia hartzen du, beti ebidentzia zientifikoan oinarrituta eta legediak esaten duenari jarraituz. Bertan hartzen diren erabakiek ospitaleko zuzendari medikoaren azken onespena behar dute. Beste kasu batzuetan azken erabakia Osakidetzako Farmaziako Batzorde Korporatiboaren esku egongo da(3).

- FTKEa paziente askotan erabiltzen denean, beharrezko tramitazioak errazteko "Ospitaleko Farmaziako Batzorde Farmakoterapeutikoan" edo "Egoera Berezietarako Sendagaien" batzordean barne-protokolo kliniko bereziak aurkeztu eta baimentzen dira ebidentzia zientifikoari helduta. Protokolo horiekospitaleko agintarien oniritzia jaso behar dute gaixoei beren erabilera eskaini ahal izateko.

Gogoratu behar dugu, kasu guztietan derrigorrezkoa dela gaixoaren baimena dokumentatuta edukitzea, "baimen informatua" deritzona. Ezin dugu ahaztu hau guztia gaixoak onartu behar duela lehenik eta behin (4).

Sendagai bat fitxa teknikoz kanpo erabiltzen denean, ezin dugu ahaztu ager daitezkeen ondorio kaltegarri posibleak farmakozaintzako sare nazionalaren bidez jakinarazi behar direla (5). 
Euskal Autonomia Erkidegoan inspektoreek FTKEko preskripzioak ez dituzte baimentzen. Horren ondorioz, egoera honetan onartutako tratamendua gaixoak ospitaleko farmazietan jaso behar izaten du.

\section{Espainian baimendu gabeko sendagaien eskuratzea: atzerriko sendagaia}

Sendagaia ez dago eskuragarri estatuan, baina behar dugun indikazio horretarako eskuragarri dago legalki beste herrialde batean. Honenbestez, salbuespen gisa Sendagai eta Osasun Produktuen Espainiar Agentziak (SOPEA) Espainian merkaturatzen ez den sendagai hori eskuratzeko aukera eman dezake.

Horretarako honako egoeraren baten aurrean egon behar dugu:

- Espainian, pazienteak behar duen sendagaia konposizio konkretu horretan ez egotea edo gaixoaren tratamendua aurrera eramateko beharko litzatekeen forma farmazeutikoan. Adibidez, leuzemia batzuetan merkaptopurina sendagaia erabili behar da. Merkaptopurina 50 mg konprimatu sendagaia Espainian merkaturatuta dago, baina ume txikietan erabili ahal izateko soluzio bezala beste herrialde batzuetan merkaturatzen den Xaluprine ${ }^{\circledR}$ lortzeko aukera dago.

- Gaixoaren tratamendurako egokia eta ezinbestekoa den printzipio aktiboa Espainian eskura ez izatea. Adibidez, tioguanina sendagaia leuzemia mota batzuk tratatzeko protokolo terapeutikoetan dago. Espainian eskuragarri ez dagoen arren, beste herrialde batzuetan merkaturatuta dagoen Lanvis ${ }^{\circledast} 40 \mathrm{mg}$ konprimatuak lortzeko aukera dago tramitazio honen bidez.

Sendagai hauek lortu ahal izateko derrigorrezkoa da gaixoaren baimena eta medikuak adierazi beharko du pazienteak beste tratamendu-aukerarikez duela. Ospitaleko farmaziaren ardura da SOPEAra eskaera egitea, baldin eta sendagaia ospitalean erabiltzeko beharra badago. Beste batzuetan, berriz, sendagaiak ez dira ospitalean erabili beharrekoak eta kasu horietan medikuak eskaera Osasun Saileko Lurralde Ordezkaritzara bidali behar du eta gaixoak han eskuratu dezake sendagaia. Edozein kasu dela, medikuak txosten klinikoa aurkeztu behar du, non argi agertu behar den gaixoak ez duela beste aukerarik egoera kliniko horretan.

Hornidura-gabetze kasuetan, sendagai bat Espainian merkaturatua egon arren, laborategia merkatuko beharrak asetzeko gai ez bada, bide honi jarraitu behar zaio. Azken aldian, egoera hau geroz eta gehiago gertatzen ari da eta merkaturatze-murrizketa hauen aurrean SOPEAk sendagaia atzerritik ekartzeko ahaleginak egiten ditu.

\section{Ikerketan dauden sendagaien erabilera errukiorra}

Ikerketa-fasean dagoen sendagai bat onartua izan aurretik, saiakuntza klinikoan parte hartzen ez duen gaixo batentzat, farmakoa eskuragarri egon daiteke "erabilera errukior" deritzonaren arabera. Aukera honetaz baliatu ahal izango dira gaixotasun kroniko bat edo beren bizitza arriskuan jartzen duen gaitz bat edo gaitz larri ahulgarri bat duten pazienteak, baldin eta ezin bazaie behar bezala tratatu baimendutako sendagai batekin.

Egoera hau askotan gertatzen da sendagaiak SOPEAren baimena eskuratzeko prozesua irekita duenean. Modu horretan, sendagaiaren erabilera haren merkaturatzeari aurreratu dakioke. Espainian merkaturatu aurretik sendagai bat erabiltzeko aukera ematen duegoera honek. Kasu hauetan, saiakuntzaren promotoreak edo merkaturatzeko eskaera egiten duenak sendagaia dohainik eskaintzen du gehienetan.

Bi prozedura mota aurki genitzake:

- Banakako eskaera: gaixo konkretu batentzat derrigorrezkoa bada saiakuntza kliniko batean murgilduta dagoen sendagai bat, baina gaixoa ezin bada saiakuntzan sartu (adibidez, errekrutamendua itxita badago). Egoera honetan baimena indibidualki eskatu beharra dago saiakuntza klinikoa aurrera eramaten ari den promotoreari. Horretaz gain, SOPEAk ere baimena 
Josune Garcia de Andoin Barandiaran, Maitane Umerez Igartua, Miren Ercilla Liceaga, June Landa Alberdi, Larraitz Leunda Eizmendi, Mikel Urretavizcaya Anton, Aitziber Lizardi Mutuberria

eman behar du. Kasu guztietan bezala tratamendu hauek tramitatzeko ospitaleko aginteen baimena eta gaixoaren onespena derrigorrezkoak dira.

- $\quad$ Aldi baterako erabilera-baimena: denbora murriztu baterako SOPEAk ikerketan dagoen sendagai baten erabilera baimendu dezake, saiakuntza oso fase aurreratu batean badago edota komertzializaziorako eskaera abiarazita badago. Kasu honetan gaixo kopurua dezente handiagoa izan daiteke eta SOPEAk baimendu dezake sendagai hori erabiltzea denbora murriztu batean (normalean sendagaiak finantzazioa lortu arte). Horrela gaixoak sendagai horren erabileraz aprobetxatzeko aukera du. Onkologia-mailan egoera hau maiz gertatzen da. Modu honetan gaixoei sendagai berri hori lortzeko aukera aurreratzen zaie.

\section{Saiakuntza kliniko batean parte hartzea}

Batzuetan pazientea tratatzeko aukera egokiena saiakuntza kliniko batean sartzea da. Pazientearen egoera kliniko konkretu horretarako irekita dagoen saiakuntza kliniko batean sartzeko aukera badugu, pazienteari aukera hori eskaini behar zaio, betiere aurrez parte hartzeko ezaugarriak betetzen dituela ziurtatuta. Gero gaixoaren esku egongo da saiakuntzan sartu nahi duen ala ez aukeratzea.

\section{Ondorioak}

Hauetako edozein egoera gertatzen bada, medikuak baimen berezi bat eskatu beharko dio ezinbestean Sendagai eta Osasun Produktuen Espainiar Agentziari (SOPEA) edo/eta ospitaleko aginteari. Horretarako, medikuaren txostena aurkeztu behar da, non argi azaldu behar den sendagai horren beharra ezinbestekoa dela. Horretaz gain, medikuak gaixoaren baimen informatua jaso beharko du tratamendu hauek aurrera eramateko, eta, beraz, gaixoa izango da azken finean sendagaia egoera berezi honetan jasotzeko azken erabakia hartuko duena. Ezin dugu ahaztu ager daitezkeen ondorio kaltegarri posibleak farmakozaintzako sare nazionalaren bidez jakinarazi behar direla beti.

\section{Erreferentzia bibliografikoak}

1. España. Real Decreto $1015 / 2009$, de 19 de junio, por el que se regula la disponibilidad de medicamentos en situaciones especiales [Internet]. Boletín Oficial del Estado. 2009 [Kontsulta 2021-02-25]; 174: 60904-60913. Eskuragarri: https://www.boe.es/eli/es/rd/2009/06/19/1015

2. España. Real Decreto 1090/2015, de 4 de diciembre, por el que se regulan los ensayos clínicos con medicamentos, los Comités de ética de la Investigación con medicamentos y el Registro Español de Estudios Clínicos [Internet].Boletín Oficial del Estado. 2015 [Kontsulta 2021-02-25]; 307: 121923-121964. Eskuragarri: https://www.boe.es/eli/es/rd/2015/12/04/1090

3. EAE. ERABAKIA, 2010eko maiatzaren 13koa, Osakidetza-Euskal Osasun Zerbitzuko Administrazioko Kontseiluarena, Osakidetza-Euskal Osasun Zerbitzuan farmaziako batzorde korporatibo bat eratu eta berari eginkizunak esleitzeko eta bere kideak izendatzeko dena [Internet]. Euskal Herriko Agintaritzaren Aldizkaria. 2010 [Kontsulta 2021-03-17]; 113: 4. or. Eskuragarri: 1003005a.pdf (euskadi.eus)

4. España. Ley $41 / 2002$, de 14 de noviembre, básica reguladora de la autonomía del paciente y de derechos y obligaciones en materia de información y documentación clínica [Internet]. Boletín Oficial del Estado. 2002 [Kontsulta 2021-03-17]; 274: 40126-40132. Eskuragarri: https://www.boe.es/eli/es/l/2002/11/14/41

5. España. Real Decreto $577 / 2013$, de 26 de julio, por el que se regula la farmacovigilancia de medicamentos de uso humano [Internet]. Boletín Oficial del Estado. 2013 [Kontsulta 2021-0403];179: 55066-55092. Eskuragarri: BOE.es - BOE-A-2013-8191 Real Decreto 577/2013, de 26 de julio, por el que se regula la farmacovigilancia de medicamentos de uso humano. 